\title{
Brood attending by females of the hyperparasitoid Trichomalopsis apanteloctena (Hymenoptera: Pteromalidae) on cocoon clusters of its host, Cotesia kariyai (Hymenoptera: Braconidae) and its effects on reproduction, development and survival
}

\author{
NAOto TAKAI ${ }^{1}$, Yutaka NAKAMATSU ${ }^{1}$, JefFrey A. HARVEY ${ }^{2}$, Ken MIURA ${ }^{1}$ and Toshiharu TANAKA ${ }^{1 *}$ \\ ${ }^{1}$ Applied Entomology, Graduate School of Bio-Agricultural Sciences, Nagoya University, Chikusa, Nagoya 464-8601, Japan; \\ e-mail: totanaka@agr.nagoya-u.ac.jp \\ ${ }^{2}$ Department of Multitrophic Interactions, Netherlands Institute of Ecology, Centre for Terrestrial Ecology, PO Box 40, \\ 6666 ZG Heteren, The Netherlands
}

Key words. Pteromalidae, Braconidae, Trichomalopsis apanteloctena, Cotesia kariyai, antagonistic behavior, brood guarding, superparasitism, koinobiont parasitoid

\begin{abstract}
Theoretical models predict that brood guarding may evolve in situations where eggs are costly to produce or when handling times are long. This study reveals that females of the secondary hyperparasitoid Trichomalopsis apanteloctena guarded cocoon broods of Cotesia kariyai, a gregarious endoparasitoid. Hyperparasitoid females also monopolized host resources and protected their offspring by driving away other conspecific hyperparasitoid females. The females exhibited antagonistic behavior towards competitors through threatening body postures, biting and chasing. Using a video camera to determine how long a hyperparasitoid female attended and parasitized cocoons within a single host brood, it was found that after about 4 days, cocoon guarding behavior became much less apparent. Moreover, more than $90 \%$ of hosts were typically parasitized by a hyperparasitoid female over the course of 4 days after she commenced brood guarding. Observations of egg production during a female's lifetime revealed a physiological interval rhythm that typically lasted 3-4 days, which correlates almost exactly with the period during which the cocoons were guarded. To confirm the giving-up time for a host cocoon brood, hyperparasitoid females were given access to 24 h-old cocoon clusters, each containing 60-100 individual cocoons. Ninety percent of the females remained on cocoons for approximately $72 \mathrm{~h}$. Furthermore, twenty-five percent of wasps continued attending and presumably guarding host cocoon broods for more than $138 \mathrm{~h}$ after the female first attended the brood. C. kariyai larvae pupate within a few hours of egression from their host and emerge as adults about 5 days $(120 \mathrm{~h})$ later. Therefore, many hyperparasitoid females continued to guard older host cocoons of greatly reduced quality as a resource for their progeny and some even after eclosion of the primary parasitoid. Late-brood guarding enabled a hyperparasitoid female to protect her own progeny from other hyperparasitoid females that readily attacked and killed them when she was removed. Our study thus reveals that extended guarding behavior is an adaptive mechanism that probably plays an important role in the survival of the original brood.
\end{abstract}

\section{INTRODUCTION}

Many species exploit resources that are distributed in discrete patches in the environment. This phenomenon is well studied in parasitoids, which are insects that develop in, or on other insects whereas the adults are free-living (Godfray, 1994). Many parasitoids have narrow host ranges, and thus only attack one or a few species in nature. Female parasitoids are therefore under strong selection pressure to find and locate suitable hosts that may be dispersed, scarce or concealed (Jervis \& Kidd, 1986). Although suitable hosts for many parasitoids are often distributed non-randomly (Godfray, 1994), successful host location may expend considerable metabolic energy that may be required for other vital functions (Lessells, 1991). Lifetime reproductive success in parasitoid wasps is limited by the number of eggs available for oviposition at a given time in the female's life or by the time that is available for locating hosts (Heimpel \& Rosenheim, 1998). In particular, hyperparasitoids (in the fourth trophic level) are constrained because their hosts may be less common or else are distributed more thinly than herbivorous hosts of primary parasitoids located further up the food chain (Brodeur, 2000; Harvey, 2008).

When hosts are scarce and aggregated, selection may result in quite divergent host exploitation strategies amongst hyperparasitoids attacking the same host. This has been shown in two species of secondary hyperparasitoids attacking cocoon clusters of $C$. glomerata. Upon encountering a host cocoon cluster, Lysibia nana typically parasitizes most or all of the cocoons in a single visit, a process that can take up to several hours (Harvey et al., 2006). However, L. nana does not host-feed, matures eggs quite rapidly, is winged and presumably disperses well within a habitat patch (Harvey, 2008). By contrast, a closely related species, Gelis agilis, must hostfeed in order to produce eggs. This species is also wingless and produces only a few eggs per day (Harvey, 2008). Because it cannot fly, G. agilis is a poor disperser

\footnotetext{
* Corresponding author.
} 
(in comparison with L. nana) and may therefore only encounter a single host cocoon brood in her lifetime. Based on differences in their biology, we may predict stronger selection for the evolution of brood guarding behaviour in G. agilis more than in L. nana.

When more than one hyperparasitoid female encounters a single cocoon brood of a primary parasitoid host, antagonistic interactions may occur between them for possession of the brood. Brood guarding by females, occasionally leading to physical conflict between them, may be an important pre-requisite to secure the resource for oviposition. Antagonistic behavior among females has been observed in primary parasitoids (both intra and interspecifically) that were attempting to acquire and monopolize hosts (Hardy \& Blackburn, 1991; Field, 1998, Field et al., 1998; Batchelor et al., 2005). For instance, on finding a host caterpillar, females of the gregarious bethylid wasp, Goniozus nephantidis paralyze it and then lay broods of 3-18 eggs on the host cuticle a day later (Goubault et al., 2007b). Females remain with their offspring until they pupate, but if a second female is encountered during development of the first female's larvae, owner-intruder contests ensue, with the loser eventually being driven away from the host (Hardy \& Blackburn, 1991; Petersen \& Hardy, 1996; Goubault et al., 2007a, b). Studies with other invertebrates have similarly reported brood guarding and parental care (Tallamy \& Denno, 1981; Cocroft, 2002).

In studying brood guarding in parasitoids, idiobionts have proven to be model subjects. Idiobionts are parasitoids that attack non-growing or paralyzed hosts (Askew $\&$ Shaw, 1986). For idiobionts, the host represents a static resource that is ostensibly fixed at oviposition, and thus host quality is determined by a host's previous nutritional history (Harvey, 2005). However, older hosts are often less suitable for parasitoid development than younger hosts because of the differentiation of body parts into wings, cuticle and appendages (Chapman, 1971, Nakamatsu \& Tanaka, 2004). Many idiobiont parasitoids also produce large yolky "anhydropic" eggs that require considerable metabolic investment per egg and require a considerable time to lay (Jervis \& Kidd, 1986; Jervis et al., 2001, 2008). At the same time, they have low potential fecundities because they attack host stages that are often scarce or difficult to find, such as pupae (Godfray, 1994). Because of these factors, each egg thus represents a valuable resource, perhaps explaining the observation of brood-guarding in this group of parasitoids.

Trichomalopsis apanteloctena (Crawford) is an idiobiont ecto-hyperparasitoid of prepupae or pupae of a variety of primary parasitoids in the genus Cotesia, e.g. C. ruficrus, C. glomerata, C. plutellae and C. kariyai (Kamijo \& Grissell, 1982). Trichomalopsis apanteloctena females must first feed on host hemolymph to obtain proteins for egg production before being able to oviposit a few days later (Jervis \& Kidd, 1986; Harvey, 2008). Following host-feeding, the wasp produces anhydropic eggs which are stored only in small numbers in the ovaries pending oviposition. After the first oviposition bout, eggs continue to be matured in small numbers interspersed with occasional host-feeding bouts to replenish protein reserves. One of its preferred hosts, Cotesia kariyai, is a gregarious koinobiont endoparasitoid whose larvae make a cocoon cluster soon after emerging from mature larvae of its lepidopteran host, the armyworm Pseudaletia separata. During the reproductive period, the adult female wasp remains on the cocoon cluster of $C$. kariyai and exhibits aggressive behavior towards other hyperparasitoid females (based on preliminary observations). Extended bouts of aggression tended to reduce the number of eggs laid by the guarding female because of the disruption of oviposition behavior (Nakamatsu et al., unpubl. data).

In this study we measured the number of eggs oviposited by $T$. apanteloctena females in cocoons of $C$. kariyai when the hyperparasitoids were not disturbed by conspecific females. More specifically, we examined the duration of brood guarding by hyperparasitoid females on cocoon clusters of $C$. kariyai, and ascertained whether the intensity of guarding by female wasps changed with time. The importance of host brood size on guarding behavior was also determined. Lastly, we also measured lifetime reproductive success in $T$. apanteloctena. Our results clearly show that brood guarding behavior in this species confers an adaptive benefit to the fitness of hyperparasitoid females by increasing the likelihood of progeny survival against the costs of protracted brood attending. Further, the physiological dynamics of egg maturation reveal that $T$. apanteloctena is probably well-adapted at exploiting gregarious parasitoids in the genus Cotesia.

\section{MATERIAL AND METHODS}

\section{Insect cultures}

All insects were maintained at $25 \pm 1{ }^{\circ} \mathrm{C}$ with a $16 \mathrm{~L}: 8 \mathrm{D}$ photoperiod. Larvae of the primary parasitoid Cotesia kariyai (Watanabe) (Hymenoptera: Braconidae) construct a cocoon cluster following egression from caterpillars of its lepidopteran host, Pseudaletia separata (Walker) (Lepidoptera: Noctuidae). The cocoon cluster is composed of an inner cocoon layer, which encloses each parasitoid pupa, and an outer cocoon layer that covers all of the individual cocoons. Pseudaletia separata has been used as a host for the primary parasitoid in our laboratory over many years, and during that time the larvae have been reared consistently on artificial diet (INSECTA-LF®, Nihon Nohsan, Kanagawa).

Colonies of the hyperparasitoid T. apanteloctena (Crawford) (Hymenoptera: Pteromalidae) have been maintained by $C$. kariyai as primary parasitoid host in our laboratory for many generations after the initial collection in cornfields in Kanoya, Kagoshima Prefecture, Japan. The hyperparasitoid was identified by K. Kamijo at Hokkaido Forest Experiment Station. Female wasps of $T$. apanteloctena were isolated immediately after emergence and kept for one day with 2- to 3-d old males for mating. Wasps were kept in plastic tubes $(3.5 \mathrm{~cm}$ in diameter, $15 \mathrm{~cm}$ in long) with a cotton plug containing absorbed 2-3\% sugar solution. Further, hyperparasitoid females were used in two age-class experimental set ups: 1-d and 3-d old.

Brood guarding behavior was observed visually or under a stereoscopic microscope with low magnification. 
Video-recording of temporal duration of cocoon attending by Trichomalopsis apanteloctena

To measure how long a $T$. apanteloctena female attends a host cocoon cluster of $C$. kariyai, a 3-day old adult hyperparasitoid females was placed in a Petri dish $(6 \mathrm{~cm}$ in diameter, 1.5 $\mathrm{cm}$ in height and covered with a lid to prevent the wasp from escaping) with a cocoon cluster containing 60-100 individuals (i.e. a typical brood size for $C$. kariyai collected in the Kanoya fields). Each Petri-dish was lid to prevent female from escaping. The behavior of the hyperparasitoid was subsequently recorded at 5 -second intervals for 6 days using a digital video recorder (Sony, Handycam DCR-HC41, using a Super NightShot plus and Color Slow Shutter function mode in darkness) fixed with tripod stand. Six Petri dishes were recorded simultaneously during one sequence and totally 24 replications were performed. Each location of an individual hyperparasitoid female was recorded on Macintosh computer connected with a video recorder.

\section{Behavior of adult $\boldsymbol{T}$. apanteloctena wasps in response to cocoon number and host age}

To determine if the decision by an attending hyperparasitoid female to abandon a cocoon cluster depended on host age, a 250 $\mathrm{ml}$ plastic cup that was perforated with $10-15$ holes was placed over the cocoon cluster. The size of the holes on the cup were only slightly larger than the body size of female hyperparasitoids in order to make it more difficult for the wasp to re-enter the arena and to return to the cocoon cluster. This device also makes it easy for the wasp to leave the arena.

\section{Parasitization rate of host cocoon brood after start of attending by $T$. apanteloctena}

Video-recording revealed the temporal duration of brood guarding of cocoon clusters by hyperparasitoid females. Preliminary experiments showed that hyperparasitoid females often re-visited cocoon broods several times after leaving from original cocoon cluster when they were kept in simple Petri dishes covered by a lid. The criterion used for giving-up time was when a female hyperparasitoid wasp left (moved off) a single cocoon brood of Cotesia kariyai and exited the arena through perforated holes and into an attached small plastic bag. This was ascertained using a video recorder (described above). Given that they were restrained in the plastic bags, many of the females did eventually manage to re-renter the arenas, but we believe that our set-up most accurately simulates patch leaving behaviour in the hyperparasitoid.

Preliminary work revealed that the "giving-up time" (the precise leaving time from host cocoon cluster) appeared to be correlated both with the number of cocoons parasitized by individual $T$. apanteloctena wasps and with changes in their physiological state due to egg depletion. To determine how progressive oviposition may lead to changes in behavior, the parasitization rate of a host brood was examined each day after start of attending on a host brood. Using one day-old cocoon clusters containing 60-100 cocoons, each parasitization rate was determined through the dissection of individual cocoons 5 days after start of attending on host (after emergence of primary parasitoids).

\section{Lifetime reproductive success in $T$. apanteloctena}

Immediately after emergence, adult hyperparasitoid females were isolated in plastic tubes with individual 2-3 day old male wasps for mating. Single clusters of 1-2 day old cocoons of $C$. kariyai were supplied daily to individual female $T$. apanteloctena wasps. The females were constantly given access to a $2-3 \%$ sugar solution until the female died. The total number of adult hyperparasitoids that emerged from the host cocoons was determined. Furthermore, to determine if fecundity differed in female wasps of different ages, reproductive success was also measured using one and three day old female hyperparasitoids for 8 days.

\section{Artificial superparasitism}

To determine why hyperparasitoid females attend cocoon clusters for extended periods (lasting several days), we manipulated cocoon clusters by removing the female wasps shortly after oviposition. Firstly individual females were allowed to attend single cocoon clusters containing 8-12 cocoons and were then removed from the clusters after $24 \mathrm{~h}$. Half of the cocoon clusters were dissected to confirm the death rate through normal development. The other half of the cocoon clusters were not destructively sampled but the hyperparasitoid eggs were allowed to hatch over the course of $24 \mathrm{~h}$. Then, another female was introduced to each cocoon cluster of $C$. kariyai. Superparasitism was ascertained by observing whether the second female killed the developing larvae from the first-female and then oviposited on the same host cocoon. At the end of the experiment, individual cocoons of $C$. kariyai were carefully dissected under a stereomicroscope.

\section{RESULTS}

\section{Preliminary observations of aggressive behavior by $T$. apanteloctena females}

Brood guarding behavior of $T$. apanteloctena was observed as follows: A: Here, adult hyperparasitoid females exhibit a curved body posture in the shape of the letter "C" (Fig. 1A). The resident female behaves aggressively towards the other by posturing with her mandibles fully opened, but without any biting or physical aggression being observed. This results in no damage to either hyperparasitoid female and thus is more akin to a "display posture". When the resident female encountered an intruder, both females exhibited curved body postures, eventually leading to the intruder leaving the host cocoons. B: The resident and the second females used their mandibles to bite each other; the dominant female actively pursued the other (Fig. 1B).

\section{Video-analysis of temporal duration of cocoon attending by Trichomalopsis apanteloctena}

We examined the factors underlying the decision of hyperparasitoid females to terminate their occupation of cocoon clusters. This behavior appeared to be correlated with a decrease in the number of unparasitized host individual cocoons as oviposition resource and with physiological changes in the attending female wasps.

More than $75 \%$ female wasps remained on cocoon clusters until about $72 \mathrm{~h}$ after start of attending, when all had left the broods (Table 1). All of the wasps that abandoned clusters remained on the upper side of the Petri dish after $96 \mathrm{~h}$ (4 days), indicating that in nature they would have left the cocoons cluster in search of other clusters.

Most activity in the wasps attending cocoon broods occurred during daylight periods, although a few ovipositions occurred in darkness. Movement during periods of darkness gradually but progressively decreased during the period of host cocoon attendance. 


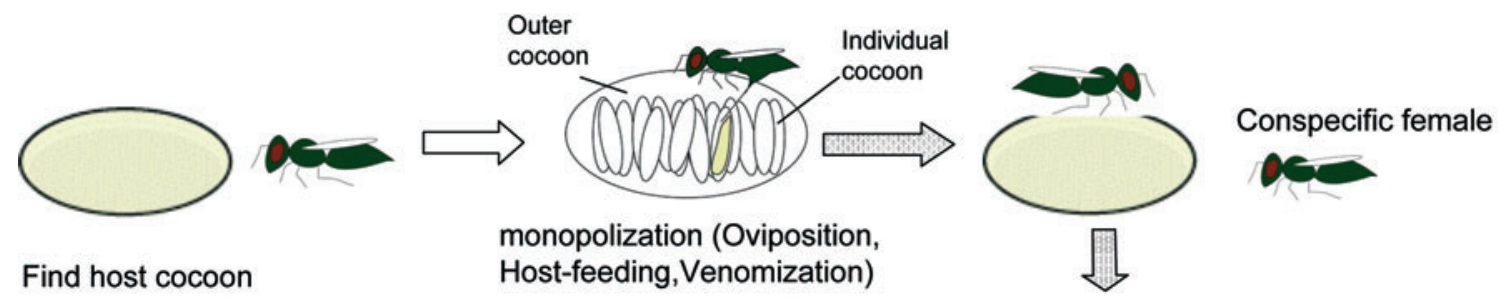

Find host cocoon Host-feeding,Venomization)
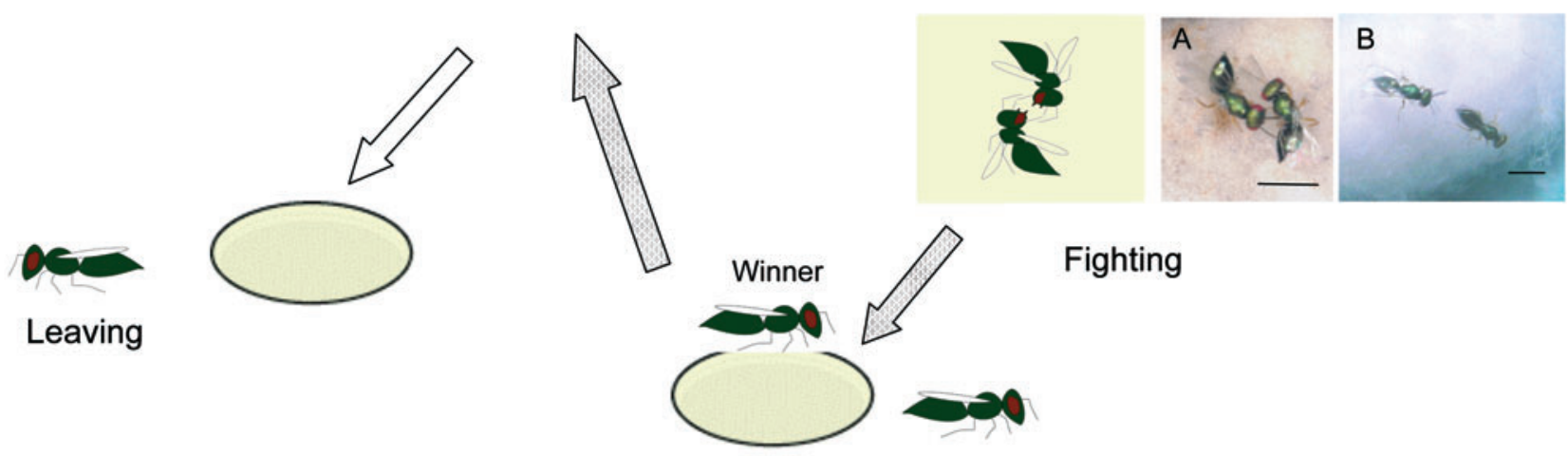

Loser escape

Fig. 1. Monopolization of host cocoons by T. apanteloctena females commence after finding cocoon clusters of Cotesia kariyai. Females inject paralyzing venom into hosts, before host-feeding or oviposition. When a resident female encountered a conspecific female, it behaved as follows. A: The hyperparasitoids exhibit a body posture in the shape of the letter "C". The resident female behaves aggressively towards the other, but without biting being observed. B: The resident female and the second female bite each other female using their mandibles and the dominant wasp pursues the other wasp. The winner continued exploiting the patch and left the host cocoon cluster about 4-5 days later.

\section{Parasitism rate of host cocoon brood after start of attending by $T$. apanteloctena}

The parasitism rate of cocoon clusters that were attended by female wasps increased gradually over time (Fig. 2). Furthermore, almost all hosts in a cocoon cluster were parasitized if the female attended the cocoons for up to $96 \mathrm{~h}$ (Fig. 2). After this time, however, the value of the cocoon cluster as an oviposition resource was lost, and this closely matches the duration of brood guarding by adult female $T$. apanteloctena wasps (Table 1).

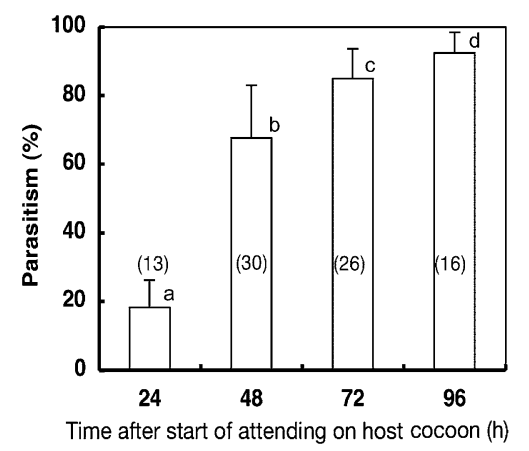

Fig. 2. Parasitism rate of Cotesia kariyai cocoon clusters containing $60-100$ cocoons by Trichomalopsis apanteloctena as a function of time after monopolizing host cocoons. Sample sizes are described in each column. Line bars represent standard deviation. Different letters above each column indicate significant differences (one way-ANOVA, $\mathrm{F}_{3,81}=111.30, \mathrm{P}<0.01$ ).

\section{Lifetime reproductive success in $\boldsymbol{T}$. apanteloctena}

To examine physiological changes in hyperparasitoid females after emergence, 1-day old host cocoon clusters were constantly provided to female wasps until death. Fresh cocoon clusters were provided daily. Female wasps laid a maximum of 67 eggs per day and a mean number of $590 \pm 220$ eggs over their lifetime $(n=18)$. Two oviposition peaks were observed to occur at 3-4 day intervals (Fig. 3). Thus, egg production in female wasps increased over the first 3 days following the initiation of oviposition, and then decreased for 2-3 days followed by a second increase in the rate of oviposition. Furthermore, this physiological rhythm was shown to be consistent in

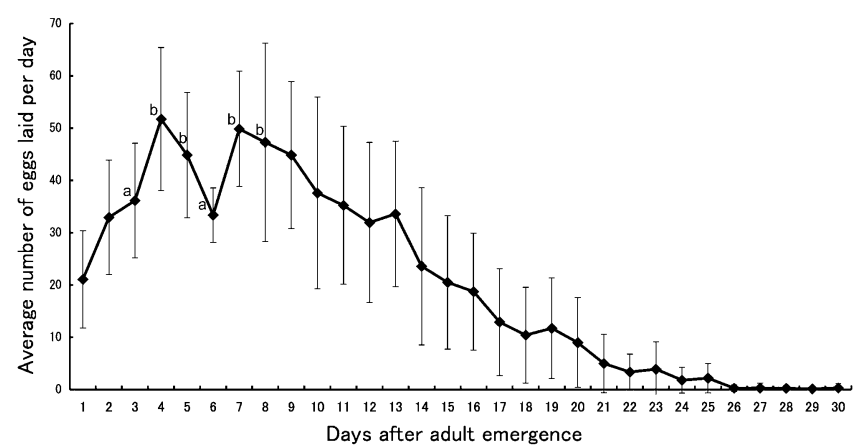

Fig. 3. Mean daily fecundity in Trichomalopsis apanteloctena females presented daily with more than 80 individual cocoons of Cotesia kariyai, as a function of the age of the female ( $\mathrm{n}=$ 18). Line bars represent standard deviation. Statistical analysis was performed among the 6 points. Different letters near each point indicate significant difference (one way-ANOVA, $\mathrm{F}_{5,72}=$ $10.38, \mathrm{P}<0.01)$ 
TABLE 1. The position of individual female Trichomalopsis apanteloctena wasps from the point at which the wasps began attending cocoon masses of their host, Cotesia kariyai. A change was recorded when the female moved from an attended cocoon cluster to the bottom or lateral side or lid of the Petri dish over the course of $24 \mathrm{~h}$.

\begin{tabular}{|c|c|c|c|c|c|c|c|}
\hline \multirow{2}{*}{\multicolumn{2}{|c|}{ Position of wasp ${ }^{1}$}} & \multicolumn{6}{|c|}{ Lapse time (hours) from start of female attending (days) } \\
\hline & & $0-24(0-1)$ & $24-48(1-2)$ & $48-72(2-3)$ & $72-96(3-4)$ & $96-120(4-5)$ & $120-144(5-6)$ \\
\hline \multirow[t]{2}{*}{ Petri dish } & $\begin{array}{l}\text { Bottom or } \\
\text { lateral side }\end{array}$ & 0 & 0 & 3 & 7 & 2 & 0 \\
\hline & Lid & 0 & 0 & 0 & $6^{2}$ & 5 & 1 \\
\hline \multicolumn{2}{|c|}{ On cocoon cluster } & 12 & 12 & 9 & 0 & 5 & 11 \\
\hline
\end{tabular}

${ }^{1}$ Females position was recorded every 5-second interval time for $144 \mathrm{~h}$ (6 days) with DCR-HC41 Handycam using Super NightSpot Plus function with infra-red ray (Sony). Twelve replications were performed.

${ }^{2}$ A female moved from lateral side to lid of Petri dish during $24 \mathrm{~h}$.

1-day old and 3-day old female wasps (Fig. 4). Both 1-day old and 3-day old female wasps showed a similar pattern in egg production that increased over the first 5 days and then decreased and increased again (Fig. 4).

\section{Observations of temporal duration of cocoon attending by $T$. apanteloctena}

We observed that some hyperparasitoid females returned to attend cocoon clusters after initially leaving them. This observation suggested the possibility that the duration of cocoon attending by female wasps under natural conditions may be shorter than that observed in the laboratory, where the insects are enclosed in arenas. Using $200 \mathrm{ml}$ plastic cups with perforated holes we limited the ability of females to return to broods that they had previously attended. Although about $90 \%$ of the females remained on 1-day old cocoon clusters containing 60-100 cocoons for approximately $72 \mathrm{~h}$, the number of wasps attending cocoons decreased to less than $50 \%$ after $102 \mathrm{~h}$ (Fig. 5). On the other hand, in the case of 1-day old cocoon clusters containing only 8 to 12 individual

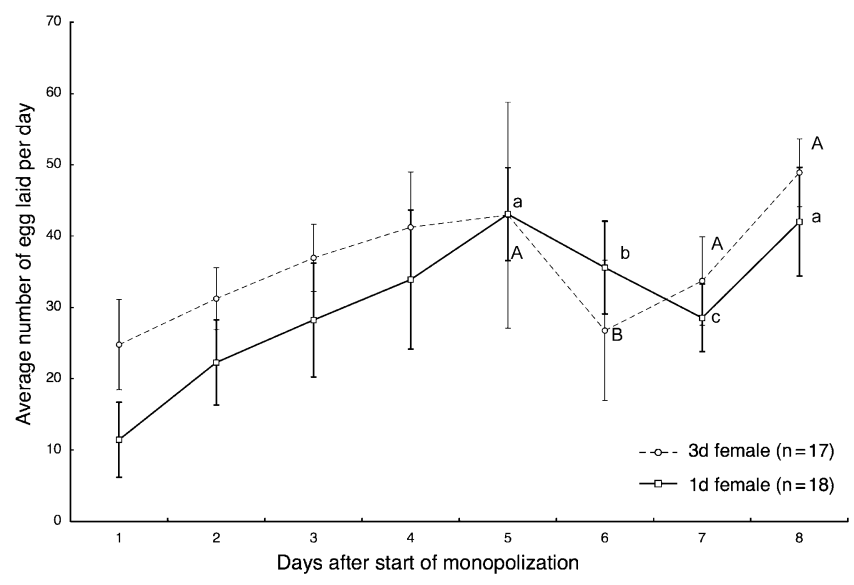

Fig. 4. Number of eggs laid daily by differently-aged females of Trichomalopsis apanteloctena. Females were one-day old (n $=18)$ or 3-days old $(n=17)$ at the beginning of the experiment. Small letters represent $1 \mathrm{~d}$ old females and capital letters represent $3 \mathrm{~d}$ old females. Line bars represent standard deviation. Statistical analysis was performed among 4 points for each aged female. Different alphabetical letters near each point indicates significant difference (one way ANOVA, 1d: $\mathrm{F}_{7,128}=17.03, \mathrm{P}<$ $\left.0.01: 3 \mathrm{~d}: \mathrm{F}_{7,128}=58.1829, \mathrm{P}<0.01\right)$. cocoons, the number of wasps attending the cocoons decreased significantly after only $18 \mathrm{~h}$ and was significantly lower than that in broods containing 60-100 individual cocoons $(p<0.01$, one way-ANOVA).

\section{Conspecific females of $T$. apanteloctena attack the eggs of other females}

When females of $T$. apanteloctena were allowed to oviposit in host cocoons and were then removed from experimental arenas, subsequently introduced females killed the larvae of the first female (Table 2). Previously developing larvae were punctured by the ovipositor of later females. The new females then remained on or in the close vicinity of the host cocoons for protracted periods, indicating that they had assumed the role of brood guarding.

\section{DISCUSSION}

This study reveals that the hyperparasitoid $T$. apanteloctena is able to monopolize and parasitize almost an entire brood of $C$. kariyai cocoons over the course of up to 4 days. Female wasps were found to remain on the host cocoons during this time and to defend them against conspecific females for a period long enough to optimize the chance that most or all of their offspring were able to complete their larval development. Although this was not measured here, it is likely that older progeny of the first $T$. apanteloctena females are not destroyed by late arriving female hyperparasitoids. These females would be confronted with cocoons containing large $T$. apanteloctena larvae (perhaps even pre-pupae). Given that T. apanteloctena is only known to attack primary parasitoids (mostly in the genus Cotesia), it is therefore highly unlikely that they would show any interest in cocoons containing older $T$. apanteloctena larvae. Because larvae of $T$. apanteloctena wasps feed only on primary parasitoid hosts, it may be adaptive to kill eggs or very young larvae, provided sufficient resources of Cotesia remain in the cocoons. Indeed, we found that when female wasps were physically removed from host cocoons in the first two days after initial parasitism, and another female was given access to them, the second female invariably destroyed all of the progeny of the first female. However, after 2 days the quality of the $C$. kariyai resources presumably decreases for other hyperparasitoid females because the progeny of the first have monopolized them. 


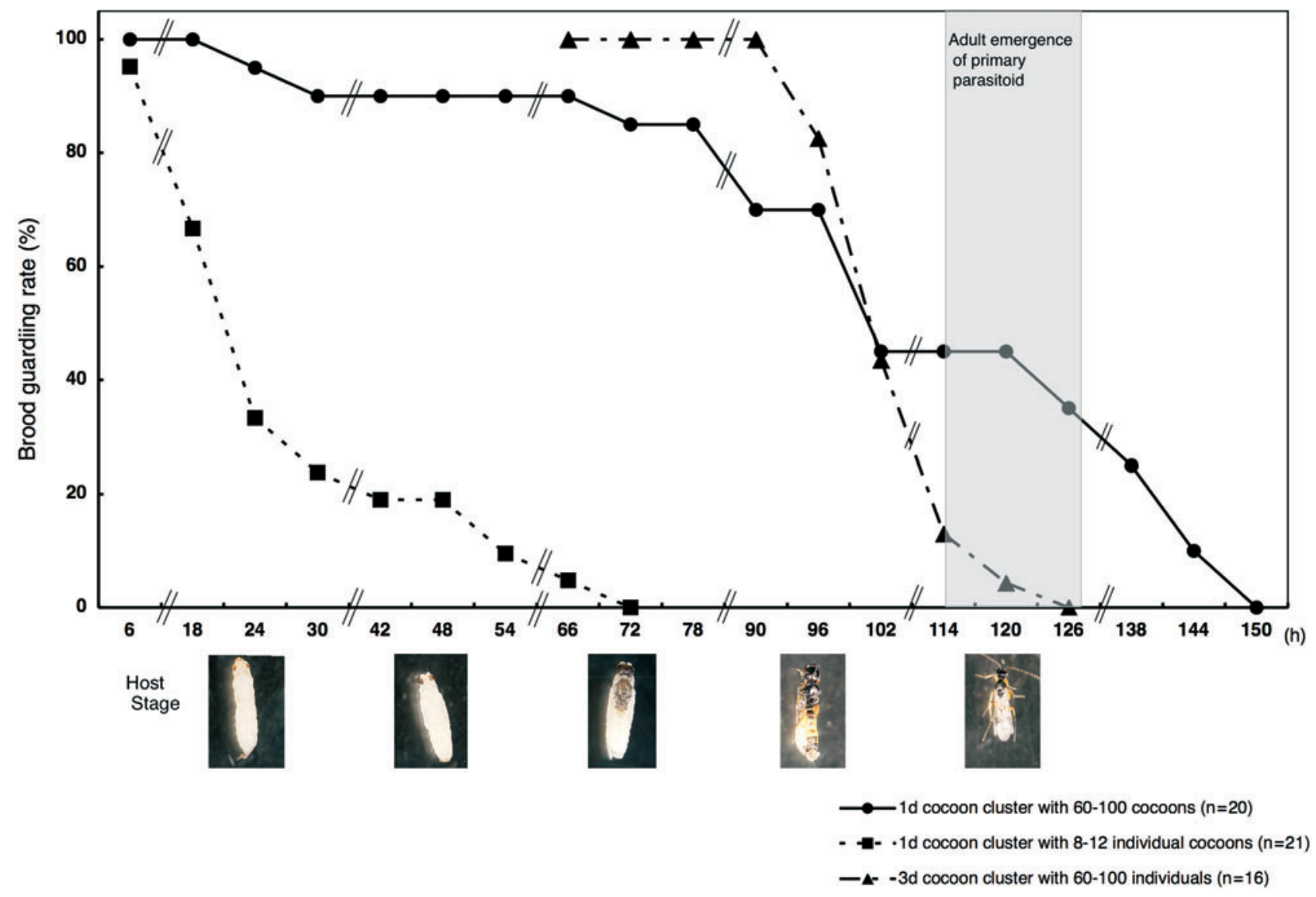

Fig. 5. Length of time (in hours) during which Trichomalopsis apanteloctena females attended cocoons of Cotesia kariyai in response to variation in host cocoon age and number of cocoons per cluster. Shaded square $=1$-day old clusters of 8-12 cocoons; closed circle $=1$-day old clusters of 60-100 cocoons; shaded triangle $=3$-day old clusters of $60-100$ cocoons. Sample size is as described on legend. Developmental stage of primary parasitoid and the host is described according to Nakamatsu \& Tanaka (2004).

Therefore extended brood attending behavior in T. apanteloctena may increase the survival of the progeny of females attending cocoons broods during the early incubation and development of their own progeny, compared with those that leave the cocoons at an early stage.

Two types of antagonistic behavior were clearly visible in $T$. apanteloctena when confronted with conspecific female wasps. Females guarding cocoon broods of $C$. kariyai often exhibited a series of threat display postures (Maynard-Smith 1982, Huntingford \& Turner, 1987) and in some cases attacked other females by biting and chasing any that attempted to gain access to the cocoons. This behavior was usually successful in allowing the resident female to retain control of the cocoon cluster (Stokkebo \& Hardy, 2000). However, 3-d old host broods were often abandoned earlier by the hyperparasitoid females

TABLE 2. Progenies of former females were killed when female occupation was obstructed and hijacked.

\begin{tabular}{lccccc}
\hline Condition & $\begin{array}{c}\text { Number of cocoon } \\
\text { clusters }\end{array}$ & $\begin{array}{c}\text { Average number } \\
\text { of cocoon per one } \\
\text { cluster }\end{array}$ & $\begin{array}{c}\text { Number of cocoon } \\
\text { clusters contained } \\
\text { dead larvae }\end{array}$ & $\begin{array}{c}\text { Percentage of indi- } \\
\text { vidual cocoons con- } \\
\text { tained dead larvae } \\
\text { per one cluster (\%) }\end{array}$ & $\begin{array}{c}\text { Percentage } \\
\text { of cocons hijacked } \\
\text { in one cluster }(\%)\end{array}$ \\
\hline $\begin{array}{l}\text { 1. Cocoons occupied } \\
\text { by one female }\end{array}$ & 18 & $10.1 \pm 0.9 \mathrm{a}$ & $4 \mathrm{a}^{3}$ & $2.2 \pm 4.2 \mathrm{a}^{4}$ & - \\
$\begin{array}{l}\text { 2. Cocoons hijacked } \\
\text { by later female }\end{array}$ & 13 & $9.8 \pm 1.3 \mathrm{a}$ & $13 \mathrm{~b}$ & $33.0 \pm 14.7 \mathrm{~b}$ & $52.5 \pm 14.4$ \\
\hline
\end{tabular}

${ }^{1}$ One-d cocoon cluster containing 8-12 cocoons was supplied to one female for $24 \mathrm{~h}$. Each cocoon was dissected to observe the mileu of the superparasitism.

${ }^{2}$ One-d cocoon clusters containing $8-12$ cocoons were left for $24 \mathrm{~h}$ to develop the eggs oviposited by the former hyperparasitoid and were further occupied by later females for $24 \mathrm{~h}$.

${ }^{3}$ Different letter in the same column show statistical difference by Chi-square test $\left(\chi^{2}=18.4379, \mathrm{P}=1.8 \mathrm{E}-05\right)$.

${ }^{4}$ Each percentage value was compared statistically with Mann-Whitney's test after arc sign root conversion $(\mathrm{z}=12.1, \mathrm{p}<0.01)$

${ }^{5}$ Cocoon was judged as hijacked in case when previously developing larvae were crushed and newly oviposited egg was found in individual cocoons. 
than broods of 1-d old hosts. This strongly suggests that older hosts are of lower quality for development of $T$. apanteloctena progeny. Similarly, Harvey et al. (2006), working with the closely related microgastrine braconid Cotesia glomerata and its hyperparasitoids, found that host quality was a linear function of host age beginning in hosts about $60 \mathrm{~h}$ after cocoon formation. At this time the parasitoid pupae underwent a dramatic shift in development, with the notable differentiation of tissues in body parts such as wings, antennae and legs. Moreover, the cuticle also began to harden and become sclerotized and these tissues thus became much less palatable for hyperparasitoid offspring. Like the hyperparasitoids in the Harvey et al. (2006) study, T. apanteloctena inject permanently paralyzing venom into the host preceding oviposition which precludes any further host development. However, even though older hosts were presumably also paralyzed, they had developed sufficiently to be of lower quality than younger hosts.

The time spent monopolizing host cocoon broods also appeared to depend on differences in host quality. When females monopolized 1-d old cocoon clusters, over half of them were found to remain on the clusters even 5 days later. Furthermore, hyperparasitoid females often guarded host cocoon clusters possessing high quality hosts for up to $48 \mathrm{~h}$ after adult emergence of the primary parasitoid (Nakamatsu \& Tanaka, 2004). This reveals that T. apanteloctena guard their own progeny long enough to ensure that they are able to pupate. Goubault et al. (2007b) found that most females of the bethylid wasp, Goniozus nephantidis, guarded and physically defended their broods on parasitized caterpillars until they successfully pupated. Furthermore, Field et al. (1998) reported that, in the parasitoid Trissolucus basalis, successful patch defense mechanisms involved not only defense of the resource prior to oviposition, but also post-oviposition defense of offspring through the assessment of time-structure and sequence in pair-wise antagonistic contests between adult females. This reveals that prolonged periods of host guarding, even after oviposition has ceased, enables the parasitoid mother to optimize the chance of her own progeny's survival (Petersen \& Hardy, 1996; Zaviezo \& Mills, 2000; Goubault et al., 2007b).

The duration of brood guarding also depended on the number of cocoons in a brood, with large broods containing 60-100 1-day old cocoons guarded for a much longer period than small broods of the same initial age with $8-12$ cocoons. This reveals that the female wasp is able to detect the depletion of the host resource as she exploits it and that she adjusts her guarding behavior in accordance with changes in host quantity and quality.

Our results also suggest that the duration of brood guarding is influenced by resource value (Field \& Calbert, 1999; Goubault et al., 2004, 2008; Kemp \& Wiklund, 2004). In T. apanteloctena, the optimal "giving up time" when brood guarding ceased is based on the physiological rhythm of female wasps where opportunities (and subsequent benefits) of locating and exploiting other host cocoon broods are balanced against the costs that her own offspring will be destroyed by other females after she has abandoned the cocoon cluster (Field, 1998; Goubault et al., 2008). Brood guarding and prolonged maternal care of offspring has been observed in only a few other orders of insects, including shield bugs (Mappes et al., 1995), rove beetles (Suzuki \& Nagano, 2006) and burying beetles (Scott, 1990).

One of the important factors that may select for brood guarding is when eggs are very costly to produce. Like other brood guarding parasitoids, including $H$. pallidus (Zaviezo \& Mills, 2000) and G. nephantidus (Hardy \& Blackburn, 1991) the hyperparasitoid T. apanteloctena produces large, yolky anhydropic eggs that require an exogenous source of proteins which are obtained through destructive host-feeding behavior (Jervis \& Kidd, 1986). Anhydropic eggs can only be produced slowly and in small numbers in most parasitoids and injecting these eggs on or into the host can take a considerable amount of handling time per egg (Harvey, 2008). By contrast, many other parasitoids produce large numbers of small, hydropic eggs that contain little protein, can be produced quickly and are injected rapidly into the host (Jervis \& Kidd, 1986). In hydropic parasitoids, maternal care would greatly reduce the number of hosts that could be encountered and would invariably be costly for the fitness of the female parasitoid. By contrast, when hosts are scarce or hard to find, selection might favor a reduction in egg production but an increase in brood care, especially if this is correlated with maternal fitness.

In this study we have reported that there is a strong physiological match between rates of egg maturation and the temporal duration of brood attending in the hyperparasitoid, T. apanteloctena. Brood attending appears also to be linked with the suitability of hosts which declines in older hosts. Moreover, given that conspecific females readily destroy eggs and young larvae of other females, brood guarding may increase the survival of the progeny of the attending female, although this remains to be examined. Future studies should also determine if there is a link between host-feeding behavior, egg maturation strategies and brood guarding in parasitoid wasps as we have suggested here. If this is verified, it would be interesting to identify the threshold (if any) between the amount of metabolic resources invested per egg and/or handling time as this selects for the evolution of brood guarding behavior in these insects.

ACKNOWLEDGEMENTS. We wish to thank K. Kamijo of Hokkaido Forest Experimental Station for helping in identification of the insects. Part of this study was supported by a Grantin-Aid for scientific research from the Ministry of Education, Science, Sports and Culture of Japan.

\section{REFERENCES}

AsKew R.R. \& SHAw M.R. 1986: Parasitoid communities: their size, structure and development. In Waage J. \& Greathead D. (eds): Insect Parasitoids. Academic Press, New York, pp. 225-264.

Batchelor T.P., Hardy I.C.W., Barrera J.F. \& Pérez-Lachaud G. 2005: Insect gladiators. II: competitive interactions within and between bethylid parasitoid species of the coffee berry 
borer, Hypothenemus hampei (Coleoptera: Scolytidae). Biol. Contr. 33: 194-202.

Brodeur J. 2000: Host specificity and trophic relationships of hyperparasitoids. In Hochberg M.E. \& Ives A.R. (eds): Parasitoid Population Biology. Princeton University Press, Princeton, New Jersey, pp. 139-162.

ChapMAn R.F. 1971: The Insects: Structure and Function. Elsevier Press, New York, 819 pp.

Cocroft R.B. 2002: Maternal defense as a limited resource: unequal predation risk in broods of an insect with maternal care. Behav. Ecol. 13: 125-133.

FIELD S.A. 1998: Patch exploitation, patch-leaving and preemptive patch defence in the parasitoid wasp Trissolcus basalis (Insecta: Scelionidae). Ethology 104: 323-338.

Field S.A. \& CALBerT G. 1999: Don't count your eggs before they're parasitized: contest resolution and the trade-offs during patch defense in a parasitoid wasp. Behav. Ecol. 10: 122-127.

Field S.A., Calbert G. \& Keller M.A. 1998: Patch defence in the parasitoid wasp Trissolcus basalis (Insecta: Scelionidae): the time structure of pairwise contests, and the "waiting game". Ethology 104: 821-840.

GODFRAY H.C.J. 1994: Parasitoids-Behavioral and Evolutionary Ecology. Princeton University Press, New Jersey, 473 pp.

Goubault M., Fourrier J., Krespi L., Poinsot D. \& Cortesero A.M. 2004: Selection strategies of parasitized hosts in a generalist parasitoid depend on patch quality but also on host size. J. Insect Behav. 17: 99-113.

Goubault M., Cortesero A.M., Poinsot D., Wajnberg E. \& Borvin G. 2007a: Does host value influence female aggressiveness, contest outcome and fitness gain in parasitoids? Ethology 113: 334-343.

Goubault M., Scott D. \& Hardy I.C.W. 2007b: The importance of offspring value: maternal defence in parasitoid contests. Anim. Behav. 74: 437-446

HaRdY I.C.W. \& BlackBURN T.M. 1991: Brood guarding in a bethylid wasp. Ecol. Entomol. 16: 55-62.

HARVEY J.A. 2005: Factors affecting the evolution of development strategies in parasitoid wasps: the importance of functional constraints and incorporating complexity. Entomol. Exp. Appl. 117: 1-13.

HARVEY J.A. 2008: Within-guild variation of reproductive strategies in the pupal hyperparasitoids Lysibia nana and Gelis agilis (Hymenoptera: Ichneumonidae). Evol. Ecol. 22: 153-166.

Harvey J.A., Vet L.E.M., Witjes L.M.A. \& Bezemer T.M. 2006: Remarkable similarity in body mass of a secondary hyperparasitoid Lysibia nana and its primary parasitoid host Cotesia glomerata emerging from cocoons of comparable size. Arch. Insect Biochem. Physiol. 61: 170-183.
Heimpel G.E. \& Rosenheim J.A. 1998: Egg limitation in parasitoids: a review of the evidence and a case study. Biol. Contr. 11: $160-168$.

Huntingford F. \& Turner A. 1987: Animal Conflict. Chapman \& Hall, New York, 448 pp.

Jervis M.A. \& Kidd N.A.C. 1986: Host feeding strategies in hymenopteran parasitoids. Biol. Rev. 61: 395-434.

Jervis M.A., Heimpel G.E., Ferns P.N., Harvey J.A. \& Kidd N.A.C. 2001: Life-history strategies in parasitoid wasps: a comparative analysis of "ovigeny". J. Anim. Ecol. 70: 442-458.

Jervis M.A., Ellers J. \& Harvey J.A. 2008: Resource acquisition, allocation, and utilization in parasitoid reproductive strategies. Annu. Rev. Entomol. 53: 361-385.

Kamijo K. \& Grissell E.E. 1982: Species of Trichomalopsis Crawford (Hymenoptera, Pteromalidae) from rice paddy, with descriptions of two new species. Kontyu (Tokyo) 50: 76-87.

Kemp D.J. \& WiKLund C. 2004: Residency effects in animal contests. Proc. R. Soc. Lond. 271: 1707-1711.

LESSELLS C.R. 1991: The evolution of life histories. In Davies N.B. \& Krebs J.R. (eds): Behavioural Ecology: An Evolutionary Approach. Blackwell Scientific Publications, Oxford, pp. 32-68.

Mappes J., Kaitala A. \& Alatalo R.V. 1995: Joint brood guarding in parent bugs - an experiment on defence against predation. Behav. Ecol. Sociobiol. 36: 343-347.

Maynard-SMith J. 1982: Evolution and the Theory of Games. Cambridge University Press, 244 pp.

NaKamatsu Y. \& TanaKa T. 2004: Food resource use of hyperparasitoid Trichomalopsis apanteloctena (Hymenoptera: Pteromalidae), an idiobiotic ectoparasitoid. Ann. Entomol. Soc. Am. 97: 994-999.

Petersen G. \& Hardy I.C.W. 1996: The importance of being larger: parasitoid intruder-owner contests and their implications for clutch size. Anim. Behav. 51: 1363-1373.

Sсотт M.P. 1990: Brood guarding and the evolution of male parental care in burying beetles. Behav. Ecol. Sociobiol. 26: $31-39$.

Stokkebo S. \& Hardy I.C.W. 2000: The importance of being gravid: egg load and contest outcome in a parasitoid wasp. Anim. Behav. 59: 1111-1118.

Suzuki S. \& Nagano M. 2006: Resource guarding by Ptomascopus morio: Simple parental care in the Nicophorinae (Coleoptera: Siplhidae). Eur. J. Entomol. 103: 245-248.

Tallamy D.W. \& Denno R.F. 1981: Maternal care in Gargaphia solani. Anim. Behav. 29: 771-778.

Zaviezo T. \& Mills N. 2000: Factors influencing the evolution of clutch size in a gregarious insect parasitoid. J. Anim. Ecol. 69: $1047-1057$.

Received April 10, 2008; revised and accepted August 15, 2008 